\section{The Plebiscite}

SIR,-I agree with several of your correspondents that the plebiscite paper was too lengthy and difficult to understand Many believed that if they replied "No" they jeopardized their future opportunities for work in any hospital, such being at the disposition of a Minister who has not shown understanding of the personal relationship of doctor and patient. His attitude of "abhorrence" of what seems to us normal and right proves his ignorance of our profession. As a matter of fact even many of the public mistakenly believe that when a practice has been sold they are obliged to summon the new doctor who has bought the practice. They do not know that they have a right to go to any doctor whom they prefer. Possibly Mr. Bevan has the same misapprehension, which would explain his "abhorrence" of the sale. In reality a sale implies that a suitable successor is likely to follow; and that he is introduced to the patients, with complete notes of their maladies and of the important matters in their family history.

Here is the true history of a case which would have suffered sadly under Mr. Bevan's dictatorship. An elderly physician, full of wisdom, contracted tuberculosis from a patient and was slowly dying. He had a large family, and was in despair as to their future, as he had been a bad business man and could have left no money for the children's education. He saw several young men who were keen to buy his large practice; he selected the one most suitable and for a whole year was able to pass on to him his experience and his wisdom. The young man was grateful and soon able to redeem his debt for the purchase of an inimitable opening; and all the patients stayed with him, equally grateful that the younger man had full information as to their condition and the remedies best suited to them.-I am, etc.,

London, W.1.

Agnes Savill.

\section{Objectionable Certificates}

SIR,-Ministers of religion, relieving officers, medical practitioners, and other qualified persons are being asked to sign confirmatory certificates for the Ministries of Pensions and Social Security, the Army, and other departments, in which they are asked to certify that "the claimant is known to me personally and that all the statements in this claim are true to the best of my knowledge and belief." (Forms C.P.1., W.P.1., M.N.1., and O.A.P.17.) I submit that in spite of the saving clause the latter half of this certificate is objectionable because the witness is being asked to warrant the accuracy of the claimant's answers to questions on a wide range of subjects of which the witness cannot possibly be fully informed. A commissioner for oaths will only attest a claimant's declaration on oath that the statements he has made are true. A medical practitioner or other witness should not be asked to combine the roles of guarantor and unqualified commissioner.

In my opinion a suitable formula is that used by the Ministry of Pensions (L.C.109): "I hereby certify that the foregoing declaration was signed this day in my presence and I believe $\mathrm{him} /$ her to be the person who he/she represents himself/herself to be. Signed." This certificate should be sufficient to satisfy all parties. The supplementary inquiries found on certain forms as to whether the witness is the claimant's employer, regular medical attendant (A.F.O.1842A), or practising within five miles of the claimant's residence are completely irrelevant and unnecessary.-I am, etc.

$$
\text { Leeds. }
$$

\section{J. H. E. MOORE.}

\section{Physiology of Vision}

SIR,-I really must protest against the travesty of my discoveries presented by Prof. H. Hartridge (Sept. 28, p. 473). I discovered that the responses of the "eye" to its natural stimulation by light had their parallels in the stimulation of beating hearts by drugs. Previous to Burridge it was firmly believed that these parallels ought to be found in the phenomena elicited by the application of electric currents to the frog's muscle-nerve preparation. Actually the parallels were never found, with the result that a science of visual stimulation has grown up which is a collection of conflicting theories, each of which attempts to rationalize some one fact of visual stimulation with the assumption that a parallel ought to be found in that muscle-nerve preparation. When I first made that discovery the stimulating drugs were unknown. It now seems likely that acetylcholine functions as the drug in respect of the central nervous system, and that some of the "drugs" produced by the action of light on visual purple stimulate the end-organs of the eye. But, judging by the theories produced, many physiologists still believe that a drug "ought" to act like an electric current.

Having found that a retinal end-organ behaved like a beating heart, I tried out the possibilities that amplitudes determined brightness and rates determined colour, and they worked. Granit is now proving that rates and colours are associated. But also, if "eyes" behaved like beating hearts, it should be possible to augment strengths and slow rates as well as to augment and quicken. When I first used these facts not enough was known about visual purple to make full use of it. Now I teach my students that it seems to me likely that different lights produce different "visual-drugs" from visual purple and that some of these "drugs" augment and quicken while others augment and slow.

From this new standpoint my students just work things out; they learn in fact to predict colour phenomena. Thus, denoting the normal retinal rate by the letter $n$, then any colour based on quickened rates becomes denotable by the term $(n+x)$, and any colour based on slowing may have its rate denoted by the term $(n-x)$. My students then just put $(n+x)$ and $(n-x)$ together, as it were, and deduce that every colour "ought" to have an opposite or complement such that when the two act together they should give a common result. What is thereby predicted is; and the student learns in a few lines more about the neutrality of grey or white than can be taught in a whole chapter of attempted explanations.

Prof. Hartridge refrained from accepting the challenge that a valid theory of dark adaptation would provide an explanation of the colours of Benham's top. In contrast with this my students here, in the examination held at the end of their first term of study, were able to give satisfactory replies to a question wherein they were required to show that the existence of dark adaptation was compatible with the artist's division of colours into the warm, cold, and neutral. To Prof. Hartridge such a question could well savour of madness, but my students answered it in a few lines because it was so easy.-I am, etc.,

Rangoon.

W. BURRIDGE.

\section{Micturition after Vaginal Plastic Operations}

SIR,-I was interested to read of Mr. A. A. Gemmell's method of dealing with the bladder after vaginal repair operations by the instillation of $0.5 \%$ mercurochrome (Nov. 30, p. 833). I have no statistics to offer, but it might be of interest to some were I to detail briefly my postoperative treatment for such cases which I have employed for many years with satisfactory results.

It is impossible to tell beforehand which patient will have reflex retention of urine, but a considerable number do have that complication, so I try to forestall it. After the operation is finished, a single gauze swab soaked in paraffin and flavine is inserted right up to the vault of the vagina as a light pack, the end just protruding from the orifice of the vagina. This is left in for 48 hours. An indwelling rubber catheter is also retained in the bladder for the first 48 hours. A clip is put on the catheter and released periodically. The bladder is never allowed to contain more than a few ounces of urine and is kept well below the normal distension limit. If the bladder is allowed to distend, due to reflex retention, the patient suffers much distress and the operation may be prejudiced by strain on the catgut sutures. If the clip is not released sufficiently frequently, some urine may escape at the side of the catheter and the wound may be wet with urine. It is seldom that patients have any trouble with micturition after the catheter is removed. If this does occur, however, it may be replaced for another two or three days. I am satisfied that there is far less risk of infection of the bladder in this method than if a catheter has to be passed repeatedly, however carefully as to asepsis. An over-distended bladder certainly predisposes to infection. This condition is akin to that found with residual urine.

The paraffin-flavine pack serves five purposes: (1) It is soothing to the tissues. (2) It is antiseptic. (3) It tends to prevent 
immediate adhesions from forming between the anterior and posterior wounds. (4) When removed it carries away with it any blood or clots that may be lying in the vagina. (5) It prevents urine from running into the vagina. There is special liability for this to happen when a patient is lying on her back. From the very beginning of the first week in bed the patient is encouraged to move the lower limbs, especially the ankle joints, freely in order to obviate the risk of venous stasis with the possibility of clotting and embolism.

Patients are kept lying in bed after operation, without once raising themselves or being raised, for two weeks. During the third week they are free to sit up in bed. At the end of three weeks they get up. A few days later they are allowed home, but are given special instructions as to carefulness about refraining from any undue strains for the next two months. Before leaving hospital they are examined, a finger being inserted into the vagina so that any small plastic adhesion between anterior and posterior wounds may be broken down. Two months after leaving hospital the patient reports for a final examination so that the result may be assessed. I have found that this routine has given excellent results and it is quite simple to carry out as far as the nursing is concerned.- I am, etc.,

Dundee.

\section{A. E. Chisholm.}

\section{Smallpox in the Vaccinated}

SIR,-As a ship surgeon concerned with the vaccination of crews I find myself in agreement with Dr. C. Killick Millard, who recommends (Oct. 12, p. 552) that vaccination of those likely to be exposed to smallpox should be carried out on the principle of "little and often." In the course of about thirtyfive years at sea I have had to deal with smallpox on five occasions, though in only one instance was a member of the crew involved. This latter occurrence led me to reduce the interval between revaccination from two years to one year. I consider yearly revaccination a necessary and sufficient routine measure for the type of population referred to. Exceptionally, cases of modified smallpox do occur within a year of successful vaccination, and I have encountered instances of successful revaccination repeated within an interval of much less than a year; but the answer to these exceptional cases of comparatively fleeting immunity is not, I think, to reintroduce multiplemark vaccination for all but to note anyone in whom this tendency is suspected and revaccinate him more frequently.

The duration of immunity after successful vaccination appears to be a personal characteristic (possibly a family one) independent of the number of marks made on vaccinating. On the one hand one finds the man with a small solitary scar made in infancy and conferring lifelong immunity of a high degree, and on the other hand the man with one or both arms pitted with a series of multiple marks in whom immunity must be short-lived.

For the past twenty years $I$ have used the intradermal method of vaccination, and I often find it possible to obtain a successful result by this method when recent attempts by scarification have failed. In dealing with large numbers the method is timesaving as well as economical, as no primary dressing is required. Seamen who protest against revaccination can usually be persuaded to have an immunity test carried out by this method, and infants can often be vaccinated while asleep. Finally, for those interested in the study of immunity reaction the intradermal puncture affords an ideal opportunity of observing the rate of development of the areola and papule, etc. In this connexion I have carried out the procedure on myself on some sixty-odd occasions during the past few years and can testify as to its simplicity, safety, and reliability.-I am, etc.,

Rustington.

A. GARDNer.

\section{Grafts for Fractured Neck of Femur}

SIR,-I was greatly interested to see Mr. F. P. Fitzgerald's description (Dec. 7, p. 861) of his instruments and technique for the insertion of chip grafts in fractures of the neck of the femur. For some time I have been thinking and hoping that the superior osteogenic and vascularizing power of medullary grafts from the crest of the ilium would help to reduce the vexing number of cases of non-union and avascular necrosis seen in these fractures after simple nailing. I was therefore much encouraged to read that Mr. Fitzgerald's results have been very satisfactory, particularly as I have recently had a somewhat similar set of instruments made to my design and have not yet had sufficient time to judge the success of the results.

I use a one-piece pencil graft cut from the iliac crest with a saw made from thin-walled $3 / 8 \mathrm{in}$. $(0.9 \mathrm{~cm}$.) tubular stainless. steel with the teeth cut at one end-i.e., a trepanning saw. With this an excellent graft can be cut in a matter of seconds with the aid of a pneumatic drill. The graft is then shid via a cannula into a tunnel drilled into the head of the femur. I am able to insert both the graft and the nail without having to expose the femur, thus saving time and lessening shock in the most frail and ancient patients.-I am, etc.,

Bcdford.

\section{G. S. STORRS.}

\section{Amoebiasis}

SiR,-Dr. G. W. Hayward is to be corrgratulated on his excellent article on amoebiasis as seen in Italy which was published in the Journal of Sept. 28 (p. 457) of this year, and which has only recently reached me. His description of the more chronic and insidious manifestations of amoebiasis is most opportune in view of the large number of troops still returning to the U.K. from amoebic endemic areas. I would, however, beg to. disagree on certain points concerning amoebiasis as seen in India nowadays and add a few remarks concerning diagnosis. and results of treatment.

In the Far Eastern theatre during days of war frank dysenteric symptoms of amoebiasis were common, due mainly to massive infection often occurring in debilitated personnel and also to concomitant bacillary infection, the role of which will be discussed later. These cases were usually treated with sulphaguanidine either in unit lines, in field ambulances, or casualty clearing stations, with, in the majority of cases, a resultant cessation of diarrhoea. They were then returned to the fighting. line only to suffer at a later cate the inevitable relapses with diarrhoea, abdominal disturbances, loss of weight, and sometimes hepatitis. Through the long passage back to a base hospital via " normal lines of communication," during which time the patients were often inadequately treated, the disease had ample time to become chronic, the amoebic ulcers being. secondarily infected with a variety of pathogenic organisms: which seemed to prevent the anti-amoebic drugs from having their full effect. Such cases were eventually evacuated to U.K. having had many courses of anti-amoebic treatment with little effect, until the advent of penicillin plus sulphonamides, which combination clears the large bowel of secondary infection and allows the anti-amoebic drugs their full action. This course now: cures the majority of cases. Previously results of treatment in: these cases was admittedly poor, and a certain number of them perforated and died of the resultant peritonitis or succumbed to amoebic hepatitis. It must be emphasized that such cases have rarely arisen in India Command either during or since. the war, and are now, to the best of my knowledge, seldom: seen in any part of the Far Eastern theatre. They were due: mainly to the exigencies of war which caused delay in treatment, while part at least of the dysenteric symptoms was due to a co-existing bacillary infection, a finding which has been extremely common. I do not believe that the underlying amoebic infection differs from that seen in other parts of the world, for when early and adequate treatment was given to these cases they almost invariably did well.

The question of mixed infections is one of very considerable importance, and some observers go so far as to say that all cases of amoebic dysentery are primarily associated with a bacillary infection. The sequence of events is as follows. A patient is admitted with diarrhoea, the stools containing blood and mucus. Microscopically, red cells, pus cells and macrophages, Charcot-Leyden crystals, and vegetative Entamoeba histolytica are seen. If in order to clear the bacillary infection sulphaguanidine is given, the diarrhoea usually ceases, and, this being very important, red cells, pus cells, and frequently $E$. histolytica disappear from the stools, a point first described by Ransome and Stokes. This disappearance of $E$. histolytica is presumably due to healing of the amoebic ulcers by eliminating the bacillary element. It is therefore of fundamental importance that even a seemingly straightforward 